\title{
Research on the Application in Glazed Tile Heating of the Low-Carbon Catalytic Combustion Furnace of Natural Gas
}

\author{
Ran Li, Kai Fang, Shihong Zhang \\ Beijing Key Lab of Heating, Gas Supply, Ventilating and Air Conditioning Engineering, Beijing University of Civil \\ Engineering and Architecture, Beijing, China \\ Email: 457698268@qq.com, 1181218401@qq.com, shihongzhang@bucea.edu.cn
}

Received 30 April 2015; accepted 19 August 2015; published 26 August 2015

\begin{abstract}
This experiment aims to summarize the regular pattern of low-carbon catalytic combustion furnace of natural gas used in glazed tile heating. The tiles used for decorating which are heated by catalytic combustion furnace are more fine and glossy than the conventional ones, moreover, pollutant emission produced in productive process is much less than before. This conclusion may provide a new way to glazed tile heating industry, and at the same time, provide a general method of using the catalytic combustion furnace.
\end{abstract}

Keywords

Catalytic Combustion, Glazed Tile Heating, Pollutant Emission

\section{Introduction}

In China, pottery plays a significant role in people's living and production. China has a long history of ceramics manufacturing industry, which can trace back to 8000 years ago. According to the statistics, daily using ceramics, building ceramics and sanitary ceramics production all are the first one in the world, including building ceramics production which accounted for about $60 \%$ of the total output. Although ceramics industry is developing in a high speed and the production grows fast, there are still large gaps between China and developed countries in energy using efficiency. At present, China's ceramic heating industry is still dominated by coal and fuel, while the foreign furnaces, which use gas fuel, can save half of the energy consumption [1]. High energy consumption inevitably brings out high pollution, so it’s a pressing task for us to realize conserving energy and reducing emissions in ceramic industry.

As a kind of traditional architectural objects of the Han nationality, glazed tiles with colorful ceramic glaze, has been being seen as the pride of the building ceramic material for thousands of years because of its bright color and strong structure. Earlier in the Northern and Southern dynasties, glazed tile was widely used as decorations on buildings. Up to now, being highly praised by architects, glazed tile has been widely used in civil ar- 
chitecture such as factories or apartments.

Based on these aspects, the effect of low-carbon catalytic combustion tile heating cannot be ignored. Originated from the United Kingdom, lean natural gas-air mixtures using in the combustion catalytic combustion was brought to China and gradually developed into what it is now. In theory, when the temperature in a furnace is about 1200 degrees Celsius, catalytic combustion of heterogeneous catalysis discharges a very small amount of $\mathrm{CO}$, nitrogen oxides and unburned hydrocarbons [2].

With the technology, we can produce tiles without fire so that the tiles can be more fine and glossy than the conventional ones.

\section{Experimental Set-Up}

Figure 1 presents the conventional diagram about system of catalytic combustion burner. Look at the experimental set-up from the left, the flue gas analyzer is the first one. Beside the flue gas analyzer is the catalytic burner. The furnace body is connected to the catalytic combustion of burner which is installed two square catalytic honeycomb monolith every time. Every square honeycomb monoliths was $150 \mathrm{~mm}$ wide in sides of the square and $20 \mathrm{~mm}$ long, with square-shaped cells whose sectional area was $1 \mathrm{~mm} \times 1 \mathrm{~mm}$. The reaction region inside the catalysts was ended at about $10 \mathrm{~mm}$ from the monolith's entrance. The right part of burner connected with a section of pipe, which is a mixture of air and gas [3].

In order to control the flow rate of natural gas and air, GMS0050BRSN200000 natural gas meter and CMG400A080100000 air meter with $0-50 \mathrm{~L} / \mathrm{min}$ and $0-80 \mathrm{~m}^{3} / \mathrm{h}$ of full-scale range, which get electric from manostat to operate were equipped [4]. The two meters were provided electric current. Exhaust gas went into the flue gas analyzer through a hole on the left side of the burner.

Put a tile embryo on the pallet, then the air is firstly let in gas volume to $3.7 \mathrm{~m}^{3} / \mathrm{h}$, and the furnace starts running at the same time. Record the data every five minutes. After a few minutes, confirm the furnace is operating normally. The data were including temperature, concentration of carbon dioxide, carbon monoxide, nitric oxide, nitrogen oxide and methane. Initially, the door of the heating Furnace was fully opened, in order to keep the temperature not too high. When the temperature was relatively stable, the natural gas degree was adjusted into 5 $\mathrm{L} / \mathrm{min}$. At the beginning there was flame inside. When the flame extinguished and the catalytic combustion began, put the air degree into $5.7 \mathrm{~m}^{3} / \mathrm{h}$. The moment the temperature was relatively stable again, the door was shut gradually to $7 \mathrm{~cm}$ between door and doorjamb. The subsequent experiment process was the same taking the distance between door and doorjamb to $3 \mathrm{~cm}$, and then the door was completely closed. And after the door's closing, the volumes of natural gas were adjusted into 6, 7, 8, L/min, at the same time, adjust the air into 6.9, 8.1, 9.2 $\mathrm{m}^{3} / \mathrm{h}$. Until the temperature rose to 800 degrees Celsius, continued heating the tile and took about 50 minutes before finishing.

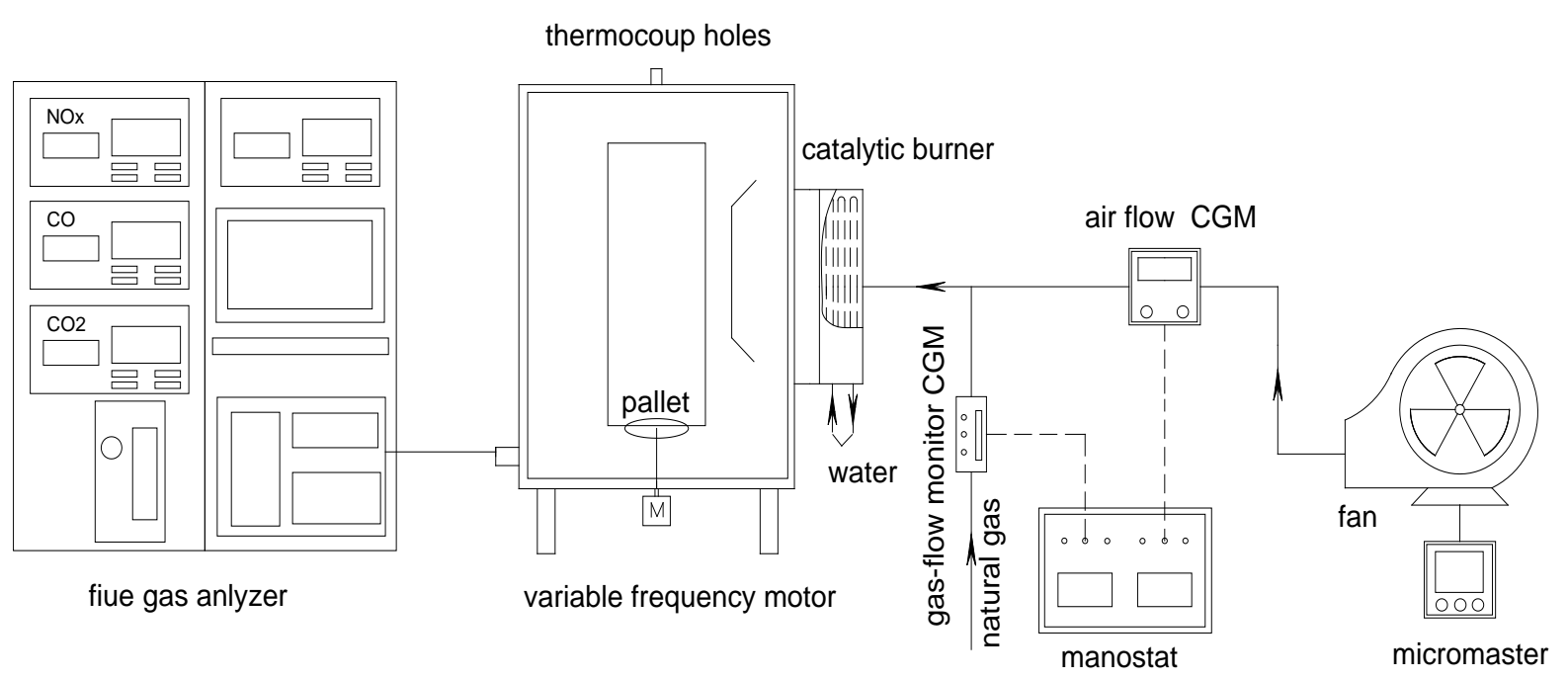

Figure 1. Combustion system of catalytic combustion burner. 


\section{Result and Discussion}

The Variation of Exhaust Gas Constituent.

Figure 2 presents the concentration of nitrogen oxide. According to the picture, when the temperature raised to about four hundred degrees Celsius, the concentration of nitrogen oxide increased rapidly. When it reached about seven hundred degrees, the concentration turned to be stable. Due to the differences of each burner, and the differences in experimental operation, every nitrogen oxide concentration's peak value and stable value are different. We infer that the reason is that the concentration of nitrogen oxide not only depends on temperature, but also depends on the environment inside the burner after closing the door. What's more, burning with flame at the beginning produced NO, but the environment inside the catalytic combustion burner gradually turned towards stability, which makes the nitrogen oxide concentration declined.

Figure 3 presents the concentration of carbon monoxide. In the process of heating glazed tile, the tile bodies released part of carbon monoxide, which caused a sudden rise of carbon monoxide after closing the door. From the figure, we find that different glazed tile released different amount of $\mathrm{CO}_{2}$, maybe because every tile's size is not the same every time. Until furnace temperature reached 800 degrees and the heating basically completed, the tiles no longer release carbon monoxide. So the carbon monoxide concentration inside the furnace gradually stabilized.

Figure 4 presents the concentration of carbon dioxide. Carbon dioxide was the most stable gas whose concentration changed regularly. Before closing the door, the concentration of carbon dioxide was the same with that in the air. When the door was closed, its concentration increased rapidly, until occupied 5\% - 6\% of the total gas, then this value was fluctuating around. The value should be the one that the environment inside catalytic combustion burner reached stable.

Products are as shown in Figure 5.

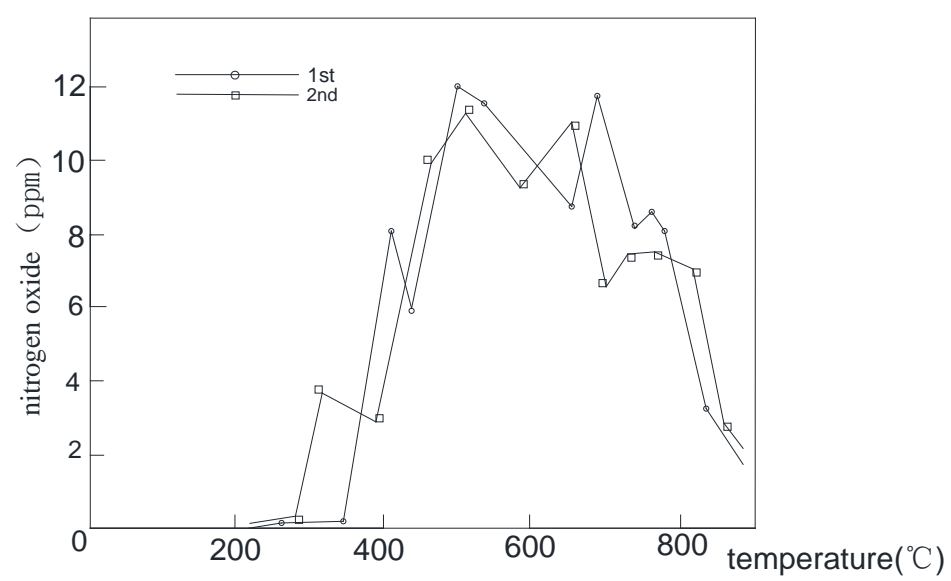

Figure 2. The concentration of nitrogen oxide.

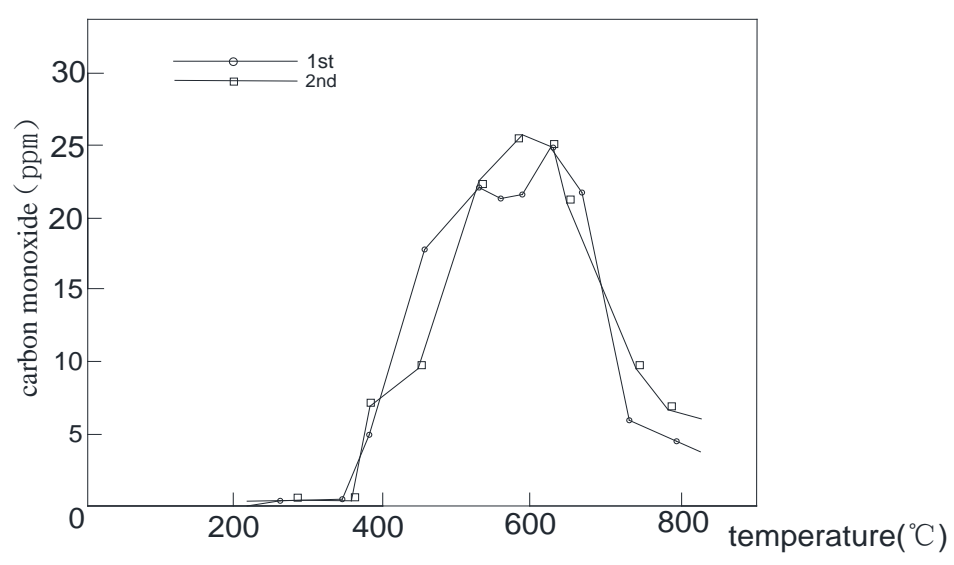

Figure 3. The concentration of carbon monoxide. 


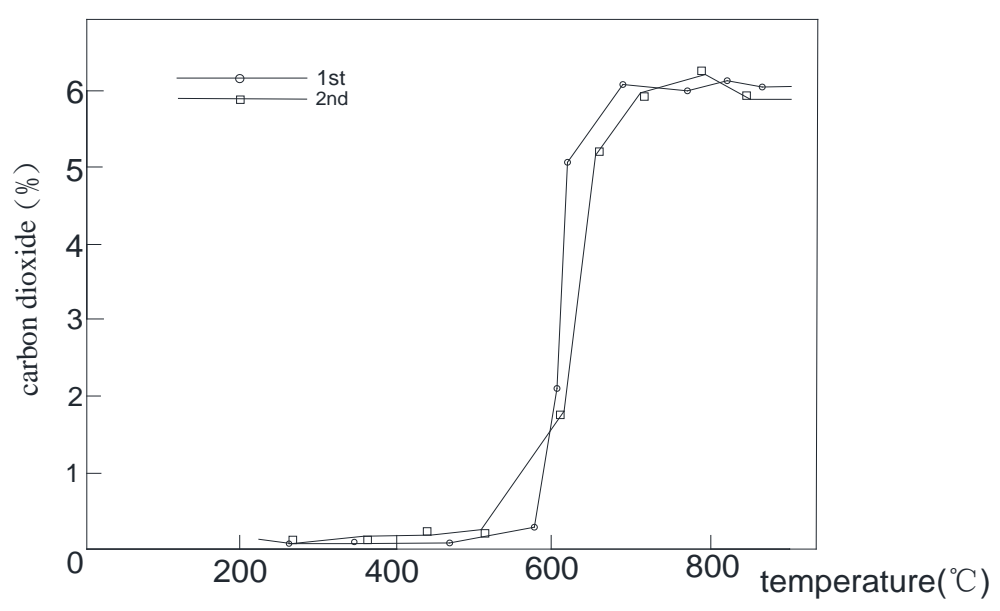

Figure 4. The concentration of carbon dioxide.

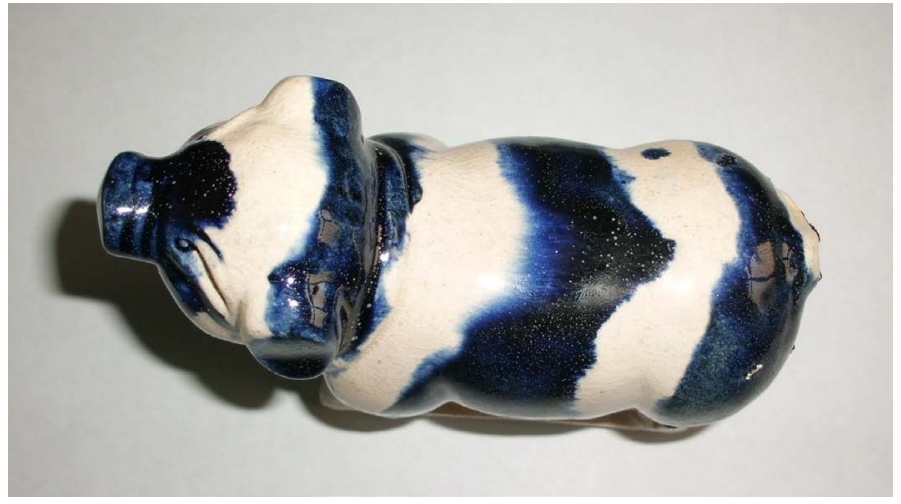

(a)

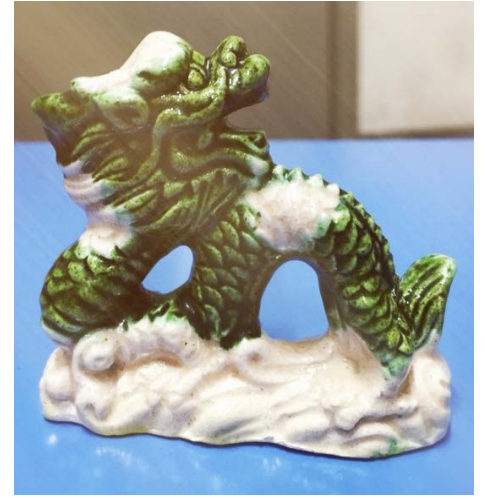

(b)

Figure 5. (a) Finished product-1; (b) Finished procuct-2.

\section{Conclusion}

Traditionally, tiles have to be heated twice and the whole process takes 11 days. During the process we must put out the fire to lower the temperature in the furnace. Furnaces burning coal and oil produce a huge quantity of smoke-pollution including $\mathrm{SO}_{2}, \mathrm{NO}_{\mathrm{x}}$ and $\mathrm{CO}$. So it's obviously that traditional methods to fire tiles cost a lot of time and cause serious environmental pollution. However, we can easily find that heating tiles with the technology of low-carbon catalytic combustion furnace of natural gas almost completely avoids sulfide production, while emissions of $\mathrm{NO}_{\mathrm{x}}$ and $\mathrm{CO}$ reduced greatly. Moreover, the natural gas catalytic combustion technology greatly suppresses the $\mathrm{N}_{2}$ becoming $\mathrm{NO}_{\mathrm{x}}$ for its low reaction temperature, so, the impact on the environment can be much smaller comparing to traditional industry.

\section{Acknowledgements}

The project was sponsored by the Beijing Municipality Key Lab of Heating, Gas Supply, Ventilating and Air Conditioning Engineering; Core Course of Heat Transfer and 2015 Funding Project (Building Environment and Facilities Engineering, Water supply and Sewerage engineering).

\section{References}

[1] Li, L.F., Jiang, F. and Zhang, Q.Y. (2012) The Technology of Energy-Saving and Emission-Reduction in Ceramic Industry. Chemical Industry Press.

[2] Zhang, S.H., Dupont, V., Williams, A. and Rickett, G. (2010) Mechanisms and Applications of Catalytic Combustion of Natural Gas in the Presence of Sulphur Compounds. The Science Press, 56-88. 
[3] Wang, X.Y., Zhu, L.Q. and Zhang, S.H. (2013) Study on Low-Carbon Catalytic Combustion Furnace of Natural Gas and the Application in Greenhouse. Advanced Materials Research, 788, 298-301.

http://dx.doi.org/10.4028/www.scientific.net/AMR.788.298

[4] Reng, B.Y., Zhu, L.Q. and Zhang, S.H. Instance of Practical Engineering Application for Professional Education. 